\title{
El médico de oficio en Colombia en las décadas de 1920 y 1930
}

\author{
Jorge Márquez*
}

Resumen: el artículo es uno de los resultados de la investigación histórica sobre la historia del estatuto del oficio de médico y de la profesionalización de la medicina en Colombia en la primera del siglo XX. En una publicación precedente habíamos precisado muchos aspectos de este problema para el periodo 1880-1920. Este artículo presenta un nuevo avance de la investigación, correspondiente al periodo 1920-1940. En él se hace énfasis en las condiciones de trabajo y la situación legal de los llamados "médicos permitidos", a quienes llamaremos también médicos de oficio, y que se caracterizaban por ejercer la medicina alopática sin poseer un diploma universitario. La hipótesis principal de este estudio es que la comprensión de los procesos históricos de profesionalización de la medicina, de normalización del arte médico y de la implantación de un monopolio médico-científico, en Colombia, presentaría una visión muy parcializada e incompleta si no se analiza el problema de los médicos sin diploma, fenómeno notable, expandido por casi todo el territorio de la nación y de muy larga duración. Para este estudio se utilizó una muestra documental compuesta de expedientes de la Junta Central de Títulos Médicos, clasificados en el fondo "Teguas" del Archivo General de la Nación de Colombia (AGN).

Palabras clave: oficio de médico; profesión médica; charlatanismo; artes de curar; historia de la medicina; Colombia; salud y trabajo.

Resumo: o artigo é um dos resultados da pesquisa sobre a história do estatuto da profissão médica e da profissionalização da medicina na Colômbia no início do século XX. Numa publicação anterior tinhamos esclarecido muitos aspectos desta questão para o período de 1880-1920. Este trabalho apresenta um novo avanço na investigação para o período de 1920-1940. Nele se faz ênfase nas condições de trabalho e o estatuto jurídico dos chamados "médicos permitidos", aos que também chamamos de médicos de escritório, e que foram caracterizados por exercer a medicina alopática sem ter diploma universitário. A principal hipótese deste estudo é que a compreensão dos processos históricos de profissionalização da medicina, a normalização da arte médica e da implementação de um monopólio médico-científico na Colômbia, apresenta uma visão muito parcial e incompleta se não for analisado o problema dos médicos sem diploma, fenômeno notável, que se

* Doctor en enseñanza y difusión de las ciencias y las técnicas Universidad París 11. Profesor Titular de la Facultad de ciencias humanas y económicas de la Universidad Nacional de Colombia. Sede Medellín. 
expandiu por quase todo o território da nação e de muito longa duração. Para este estudo se utilizaram alguns documentos do Conselho Central dos Títulos Médicos, classificados no Fundo "Teguas" do Arquivo Geral da Nação da Colômbia (AGN).

Palavras-chave: ofício médico; profissão médica; charlatanismo; artes de curar; história da medicina; Colômbia; saúde e trabalho.

\section{Introducción - El oficio de médico en Colombia en la transición del siglo XIX al siglo XX}

Es necesario resumir brevemente el estado de la investigación según los hallazgos de la primera indagación, ya recogidos en artículos de revista y capítulos de libros.

Sería engañoso comparar, según estadísticas, el estatuto social de los médicos de una sociedad a otra o de una época a otra. La condición social de los médicos occidentales del siglo XIX, por ejemplo, dependía de la noción de médico de esa época. Las formas de concebir este oficio hay que pensarlas y definirlas para cada sociedad determinada. William F. Bynum ${ }^{1}$ y Mathew Ramsey ${ }^{2}$ han mostrado cómo el estatuto del médico cambia enormemente cuando se pasa de sociedades muy afincadas en el liberalismo como modo de vida y como sistema de contraprestaciones (ej. Inglaterra y Estados Unidos), a una sociedad donde la alianza entre Universidad y Estado protegió ciertas profesiones como la farmacia, la partería y la medicina desde comienzos del siglo XIX, y donde el Estado ayudó a configurar, mediante leyes, un monopolio de la oferta médica (caso de Francia). ${ }^{3}$

En el mismo sentido, no se puede hablar de “médico", en general, o de manera uniforme, para la sociedad colombiana a lo largo de su historia. La noción de médico cambia históricamente; se modela según acontecimientos, debates y decisiones, pero también según usos sociales - no siempre ni totalmente intencionales - de las artes de curar y de las maneras de enfermarse. Estas últimas hay que entenderlas en sus varias dimensiones: a la vez como formas de considerarse individualmente enfermo o necesitado de cuidados y como formas de objetivar científica, cultural y socialmente qué es un enfermo.

En la historia de la profesión médica en Colombia, el periodo 1880-1920 se puede caracterizar como el del comienzo de la lucha universitaria y académica contra el "charlatanismo". Durante ese periodo, los médicos colombianos buscaron establecer el monopolio de la oferta de cuidados y combatir diversas prácticas informales que denunciaron como peligrosas para la salud pública. Sin embargo, los testimonios de esta lucha también permiten vislumbrar el inicio del proceso de constitución de una identidad profesional. Aunque hasta ahora la documentación que más se ha explorado es precisamente la del periodo 18801920, fuentes posteriores muestran que, en Colombia, la concurrencia (entendida a la vez como competencia y convivencia) entre las distintas artes de curar se extendió hasta muy avanzado el siglo veinte.

1 BYNUM, William et al. The western medical tradition: 1800 to 2000. Cambridge, New York: Cambridge University Press, 2006.

2 RAMSEY, Matthew. Professional and Popular Medicine in France 1770-1830: The Social World of Medical Practice. Cambridge: Cambridge University Press, 1988.

3 BYNUM, William. "Medecine et société”. In: Grmek, M. (ed.). Histoire de la pensée médicale en Occident, vol. 3, Du romantisme à la science moderne. Paris: Seuil, 1999, p. 295-317. 
La medicina institucionalizada en Colombia, a través de universidades, academias juntas de higiene, permitió conservaralgunas huellas de otras medicinas ejercidas por fuera del monopolio oficial. Los médicos universitarios no se limitaron a estigmatizar las prácticas concurrentes sino que las analizaron, intentaron conocerlas y, con frecuencia, ayudaron a legitimar algunas de ellas. Entre finales del siglo XIX y comienzos del siglo XX, el estatuto social de la profesión médica en Colombia estaba en vías de consolidación, de ahí las ambigüedades, vacilaciones e incertidumbres en la argumentación médica a favor de la reglamentación del ejercicio de la medicina. La lucha por controlar y monopolizar el ejercicio de la medicina ha sido una de las condiciones de posibilidad de la proyección política de los médicos como profesionales en la sociedad colombiana. Convencidos de su importante papel en el progreso material y en el avance de la civilización occidental en el país, los médicos de este periodo lucharon por el reconocimiento social, buscado entre sus pacientes, en general, así como por el reconocimiento político, que buscaron a través del apoyo de los poderes públicos. Esa postura ética, política y epistemológica los guió en su lucha contra el charlatanismo, y forma parte de sus reflexiones sobre "deontología médica", en las que también expresaron la preocupación por la consolidación de unos ideales positivistas de ciencia, por el reconocimiento científico y por una identidad profesional. Fue en el marco de estas discusiones y reflexiones que apareció el asociacionismo médico en Colombia como factor determinante en la conquista de una clientela y de espacios sociales para difundir y legitimar un corpus de saber, un habitus profesional y ciertas formas sociales de distinción, en resumen, para constituir una identidad colectiva como profesión.

Las relaciones entre la medicina universitaria y el Estado colombiano cambiaron a partir de 1914, porque entraron en vigencia dos leyes (Leyes 83 y 84 ) que legitimaron aún más las funciones sociales de los médicos como higienistas y educadores de la población, lo que provocó a su vez un cambio en las relaciones de fuerza entre practicantes irregulares de la medicina y médicos diplomados. Gracias a la reforma sanitaria y al fortalecimiento de un proceso de medicalización, la participación de un sector cada vez más amplio de médicos en el gobierno de la salud les otorgó más poder y consolidó el que ya detentaba la medicina universitaria como oferta terapéutica legítima para el país. Esta medicina fue investida con nuevos poderes: la presencia de los médicos comenzó a popularizarse con la extensión de prácticas como la vacunación, la institución de los "médicos oficiales" en los municipios y de los "médicos de zona" (rurales); asimismo, las oficinas locales de higiene controlaban en parte la vida cotidiana y habían aparecido nuevas instituciones ligadas a la salud como dispensarios y gotas de leche, que se sumaron a los hospitales ya existentes. La reforma sanitaria iniciada en 1914 abrió un campo de consolidación de la profesión médica. Sin embargo, las prácticas irregulares continuarían siendo un motivo de tensiones durante toda la primera mitad del siglo XX.

La Ley 12 de 1905, el Decreto 592 de 1905, la Ley 83 de 1914, la Ley 67 de 1920, la Ley 85 de 1922, la Ley 35 de 1929 y la Ley 67 de 1935, que reglamentaron el ejercicio de la medicina, tienen en común el haber sido legislaciones que dejaron un margen de tolerancia al trabajo de los médicos sin diploma, quienes podían ejercer con licencias ("la medicina pero no la cirugía"), en los municipios donde no hubiera facultativos graduados. Dichas licencias quedaban derogadas siempre que un médico graduado se instalara. No obstante, la aplicación de estas leyes estuvo muy lejos de ser uniforme.

De ahí que, en 1918, el médico Gil J. Gil publicara en la prensa comercial 
un artículo ${ }^{4}$ que llamaba la atención sobre la manera como el Departamento de Instrucción Pública de Antioquia otorgaba permisos a médicos sin diploma, con base en una interpretación "errada" de la Ley 83 de 1914. Incluso la Dirección Departamental de Higiene, en los registros mensuales de enfermedades contagiosas, ponía los nombres de algunos médicos sin diploma al lado de los diplomados, con lo cual los legitimaba y situaba en el mismo nivel. Gil J. Gil cita tres resoluciones de la Dirección General de Instrucción Pública de Bogotá, en las que se niegan permisos a algunos sin diploma, como ejemplo de la doctrina que se debía seguir en la interpretación y aplicación de la Ley 83. Si la regulación de la profesión médica variaba según la interpretación de la ley, hay que señalar también que el debate no se circunscribió al mundo médico. Las publicaciones en prensa y revistas no especializadas evidencian que los médicos divulgaron su posición en sectores sociales más amplios con la intención de movilizar la sociedad a su favor.

En este estudio mostramos que las aplicaciones, más o menos rigurosas, de las regulaciones del ejercicio de la medicina no fueron un asunto solamente jurídico sino que también variaban de acuerdo con factores económicos, sociales y culturales. No hubo una aplicación sistemática de la ley al pie de la letra, antes bien, en ella pudieron tener influencia otros factores: el grado de inserción social de los médicos permitidos en las comunidades; las relaciones que habían tejido con personas influyentes; la manera como establecían contraprestaciones a partir del ejercicio de una "profesión liberal"; el grado de aceptación que su trabajo tenía entre los médicos universitarios con diploma, y el apego o no a la medicina alopática.

\section{Reglamentación del oficio de médico en Colombia}

A comienzos del siglo XX, el ejercicio de la medicina y profesiones afines se reglamentó, pero continuó bajo una gran liberalidad, pues en cada nueva reglamentación se introducían salvedades que permitieran el ejercicio (limitado) a los llamados "médicos sin diploma", "médicos tolerados" o "médicos permitidos" y "médicos licenciados". La primera ley que regula el ejercicio de la medicina en Colombia (la Ley 12) data de 1905. ${ }^{5}$ El Decreto 592 de 1905 se emitió como reglamentación de esa ley. ${ }^{6}$ Según este decreto, además de los médicos graduados, otros podían ejercer la medicina: "Podrán también ejercer la profesión de médicos, en lugares en donde no esté establecido ningún facultativo [...] los individuos que tengan para ejercer licencia expedida por el médico titulado que esté establecido en la población más cercana". A este respecto, es muy diciente el artículo $4^{\circ}$ del mismo decreto:

Los ciudadanos colombianos que, careciendo de diploma de Doctor, estén ejerciendo actualmente la profesión de médicos, podrán continuar ejerciéndola en el lugar de su residencia, si se someten a un examen en un hospital, que verse sobre el diagnóstico y el pronóstico de la enfermedad de cuatro enfermos designados por un Consejo de

4 GIL, Gil J. "Asuntos médicos”. Colombia Revista Semanal, vol. 2, fasc. 89, p. 383-385 (1918).

5 GOBIERNO NACIONAL. "Ley 12 de 1905, por la cual se autoriza la reglamentación del ejercicio de la medicina y de la abogacía."Repertorio Oficial, Órgano del Gobierno del Departamento, Medellín: año 7, n 942, p. 5777(22 de mayo, 1905).

6 GOBIERNO NACIONAL. "Decreto $n^{\circ} 592$ (8 de junio de 1905)por el cual se reglamenta el ejercicio de la profesión de Medicina”. Repertorio Oficial, Órgano del Gobierno del Departamento, Medellín: año 8, nº 974, p. $6029-6030$ (27 de julio, 1905). 
examinadores nombrado por el Rector de la Facultad de Medicina en los lugares donde esto sea posible, o por la Junta de Higiene más próxima al lugar de la residencia habitual del peticionario.?

Realmente, lo que cambia de una legislación a otra son más que todo los procedimientos legales de otorgamiento de las licencias. En 1914 la situación jurídica del ejercicio de la medicina no había cambiado mucho. El artículo $6^{\circ}$ de la Ley $83^{8}$ de ese año continuaba respaldando la tolerancia frente a los médicos sin diploma:

Los individuos que en la fecha de la expedición de esta Ley estén en uso de licencia para practicar la medicina, sin haberse sometido al examen de que habla el artículo 4..$^{\circ}$ del Decreto número 592 de 1905, no podrán ejercer sino en aquellos lugares en donde no haya facultativos graduados. En estas mismas localidades podrán ejercer aquellos que hayan venido practicándola en un espacio, por lo menos de cinco años antes de la expedición de la presente Ley, y que hayan obtenido permiso escrito de un médico diplomado en ejercicio activo. La autorización concedida en el presente artículo caduca desde el momento en que se establezca en la localidad un médico graduado.

Parágrafo. No obstante lo dispuesto en la última parte de este artículo, las autoridades permitirán el ejercicio de la medicina (no de la cirugía), cuando así lo solicitaren por lo menos veinticinco vecinos honorables y la autoricen dos médicos graduados residentes en la localidad.

En 1914, como en 1905, el respaldo de la comunidad seguía siendo un factor decisivo para el otorgamiento de licencia o para la prolongación del ejercicio de la medicina por parte de los médicos sin diploma.

Mediante la Ley 67 de 1920,9 el Estado colombiano intentó ejercer un control más estricto del ejercicio de la medicina y profesiones afines. La novedad principal de esta ley consistió en la creación, en cada capital de departamento, de una junta examinadora de títulos médicos, compuesta por el gobernador del departamento como presidente, el director de higiene departamental, el oficial mayor de la Dirección de Instrucción Pública del Departamento como secretario, y un médico titulado (ver el artículo $2^{\circ}$ ). Entre las funciones de estas juntas estaba la verificación de la idoneidad y experiencia de individuos que aspiraban a ejercer la medicina y profesiones afines. A pesar de esta innovación y de requisitos más estrictos para la entrega de licencias, el artículo $3^{\circ}$ mantuvo la política de tolerancia frente a los sin diploma: "Toda persona que sin ser médico titulado, hubiere obtenido permiso para ejercer la medicina, deberá presentar, durante los primeros noventa días de reunida la Junta, el respectivo permiso para que ésta inscriba en la lista el nombre del agraciado y el lugar en que pudiere ejercer."Se expidió una nueva legislación reformadora, pero la permisibilidad continuó, como se lee en el artículo $2^{\circ}$ de la Ley 85 de $1922:^{10}$

7 GOBIERNO NACIONAL. "Decreto n 592 " p. 6029.

8 CONGRESO DE COLOMBIA. "Ley 83 de noviembre de 1914, por la cual se reglamenta el ejercicio de las profesiones médicas". Diario Oficial, n 5350 (23 de noviembre, 1914).

9 CONGRESO DE COLOMBIA. "Ley 67 de 1920 (noviembre 11), por la cual se reglamenta el ejercicio de la profesión médica”. Diario Oficial, n 17406 y 17407 (1920).

10 CONGRESO DE COLOMBIA. "Ley 85 de 1922 (noviembre 29) que reforma las que reglamentan el ejercicio de la profesión médica y sus auxiliares”. Diario oficial. n 18639 y 18640 (5 de diciembre, 1922). 
Pueden también ejercer la medicina y sus auxiliares: los médicos que exhiban un diploma expedido en un país con el cual Colombia tenga celebrados convenios especiales al respecto, siempre que comprueben su identidad personal y que el título respectivo tenga las autenticaciones que la ley requiere para admitir en Colombia poderes conferidos en país extranjero; los médicos extranjeros que hayan obtenido el respectivo permiso por haber llenado las condiciones prescritas en las Leyes 83 de 1914 y 67 de 1920; los individuos que sin tener título exhiban el permiso con sujeción a las leyes vigentes, y los estudiantes de medicina que hayan cursado totalmente las materias de enseñanza de las Facultades médicas nacionales. Para estos últimos el permiso se extenderá por dos años, pasados los cuales se cancelará si el estudiante no hubiere obtenido el correspondiente diploma.

Parágrafo. No obstante lo dispuesto en los dos artículos anteriores, se permitirá el ejercicio de la medicina, no de la cirugía, en aquellos lugares en donde no hubiere médico diplomado, a individuos de buena fama respecto de los cuales así lo solicitaren cuando menos veinticinco vecinos honorables de la localidad. Este permiso lo otorgarán las Juntas que se crean por la presente Ley sobre la sola vista de la solicitud, y no causará derecho alguno.

Las mismas disposiciones siguieron vigentes con la reforma de 1929, aunque esta nueva legislación (Ley 35)11 intentaba restringir aún más el proceso de concesión y revalidación de las licencias para los sin diploma. Mediante el artículo $8^{\circ}$ se creó la Junta General de Títulos Médicos: ${ }^{12}$

Para los efectos de esta Ley créase en Bogotá una Junta General de Títulos Médicos, dependiente del Ministerio de Educación Nacional, compuesta de seis profesores de la Facultad de Medicina de Bogotá, designados así: uno por el Ministerio de Educación Nacional; uno por la Academia Nacional de Medicina; uno por el Consejo Directivo de la Facultad de Medicina de Bogotá; uno por la Dirección Nacional de Higiene; uno por la Dirección de Educación Pública de Cundinamarca, y el último por la Dirección Departamental de Higiene. Será Presidente de esta Junta el señor Ministro de Educación Nacional, y secretario, el secretario de la Facultad de Medicina de Bogotá; en las capitales de Departamento, Juntas Secciónales de Títulos Médicos compuestas por el gobernador del Departamento, el Director Departamental de Higiene, el Director de Educación Pública Departamental y un médico nombrado por la Academia nacional de medicina, y en las capitales de Intendencias y Comisarias, Juntas secciónales compuestas del respectivo Intendente o comisario Especial, el Médico de Sanidad, el inspector Escolar de la Intendencia o Comisaria y un médico nombrado por la Academia Nacional de Medicina. Será Presidente de las juntas seccionales el Gobernador, Intendente o Comisario, y Secretario, el Director Departamental de Educación Pública, o el inspector escolar correspondiente.

Las funciones de la Junta General de Títulos Médicos se especificaron en el Decreto 1099 de 1930, que reglamentó la Ley 35 de 1929. ${ }^{13}$ Esta nueva legislación estableció los siguientes tipos de médicos: médicos graduados nacionales, médicos

11 CONGRESO DE COLOMBIA. "Ley 35 de 1929 (noviembre 22) por la cual se reglamenta el ejercicio de la profesión de medicina en Colombia". Diario Oficial, n² 21253, Bogotá (28 de noviembre, 1929).

12 A pesar de llamarse en la ley "Junta General de Títulos Médicos", se la denomina también, y con mucha frecuencia, "Junta Central de Títulos Médicos". Pero se trata de la misma institución. Se usará en adelante la sigla JCTM.

13 PRESIDENCIA DE LA REPÚBLICA DE COLOMBIA. "Decreto $n^{\circ} 1099$ de 1930, por el cual se reglamenta la ley 35 de 1929 sobre ejercicio de las profesiones médicas y algunas otras”. Diario Oficial, $n^{\circ}$ 21440, Bogotá (15 de julio, 1930). 
graduados extranjeros, médicos nacionales graduados en un país extranjero, médicos licenciados y médicos permitidos. Según este decreto, los "médicos permitidos" se definieron así:
a) Los que posean licencias expedidas con anterioridad a la vigencia de la Ley 35 de 1929 y con arreglo al parágrafo único del artículo $6^{\circ}$ de la Ley 83 de 1914 .
b) Los que posean licencias expedidas con anterioridad a la vigencia de la Ley 35 de 1929, de acuerdo con las leyes 83 de 1914, 67 de 1920, 85 de 1922 y los Decretos reglamentarios correspondientes, para ejercer en lugares en donde no existe establecido un médico graduado, siempre que persista esa última circunstancia; y
c) Los que soliciten y obtengan la correspondiente licencia para ejercer en lugares en donde no hubiere establecido médico graduado. Toda li- cencia de esta clase cesará tan pronto como se establezca en esas po- blaciones un médico diplomado.

Y la calidad de "médico licenciado" se definió en un parágrafo del artículo $3^{\circ}$ :

a) Los nacionales y extranjeros que hayan terminado los estudios de medicina en alguna de las Facultades colombianas y que lo comprueben en la forma ordenada por el parágrafo 20 del artículo $1^{\circ}$ de la Ley 35 de 1929; y

b) Los colombianos que hayan terminado sus estudios de medicina en el Exterior y no hubieran obtenido el respectivo diploma, siempre que presenten las certificaciones debidamente legalizadas en que conste la terminación de los estudios y el título de licenciado.

La composición de las juntas seccionales de títulos médicos se estableció en el artículo $8^{\circ}$ del Decreto 1099 de 1930:

En las capitales de los Departamentos, Intendencias y Comisarías, funcionarán las Juntas Seccionales de Títulos Médicos integradas por el Gobernador del Departamento, el Director Departamental de Higiene, el Director de Educación Pública, y un médico nombrado por la Academia Nacional de Medicina y por el Intendente o Comisario Especial, el Médico de Sanidad, el Inspector Escolar de la Intendencia o Comisaría y un médico nombrado por la Academia Nacional de Medicina. Será Presidente de las Juntas Seccionales, el Gobernador, el Intendente o el Comisario y Secretario, el Director de Educación Pública o el Inspector Escolar. Esto en cuanto lo consienta el personal existente en la respectiva localidad.

\section{"Médicos permitidos" en la primera mitad del siglo $\mathrm{XX}$ en Colombia}

En el fondo "Teguas" del AGN hay expedientes de dentistas, homeópatas, farmaceutas y alópatas. La muestra que elaboramos (ver Tabla 1) solo incluye médicos alópatas (30 en total), que ejercieron la medicina en unos 29 municipios (Jamundí, Florida, Ulloa, Quipile, La Vega, Aracataca, Girardot, Roldanillo, La Florida, Sasaima, Tenjo, Guamo, Guavatá, El Carmen de Apicalá, Villeta, Bogotá, Sopó, Nemocón, Toro, Cali, Venadillo, Alcalá, La Palma, Tuluá, Ortega, Ansermanuevo, El Líbano, Medellín, Yotoco), repartidos en 6 departamentos (Antioquia, Valle del Cauca, Tolima, Cundinamarca, Magdalena y Santander). La muestra cubre el periodo 1919-1939, 
según las fechas de solicitudes de licencia por parte de los "médicos permitidos". Sin embargo, según algunos trámites, a veces se adentra en la década de 1940. Los municipios enumerados arriba son solamente los principales, es decir, aquellos desde donde se tramita la licencia principal o su revalidación. Sin embargo, es evidente que muchos de estos "médicos permitidos" trabajaron también en otros municipios, casi siempre vecinos de su municipio principal de residencia. Aunque no eran itinerantes, sí revelan cierta movilidad espacial en el ejercicio de su oficio, debida sobre todo a la presión de las autoridades en el cumplimiento de las legislaciones que regularon el ejercicio de la medicina en Colombia entre 1905 y 1940.

Al escoger entre los oficiantes sin diploma a los "alópatas", no solo delimitamos la muestra sino que centramos el análisis en un tipo especial de médico, que ejercía la medicina adhiriendo lo máximo posible a la medicina de pretensiones científicas o medicina universitaria. Esta puede definirse como la certificada por cursos, exámenes y diplomas, basada en una gestión regulada e institucional de la enseñanza médica y de la validación de títulos. Es la misma que se convirtió en Occidente en monopolio de instituciones refrendadas por los Estados y legitimadas internacionalmente a través de la producción colectiva y de la sanción social de conocimientos científicos y técnicos y sus aplicaciones. Los alópatas que analizamos pretendieron practicar este tipo de medicina, pero sin haberse graduado como médicos.

Tabla 1

Médicos permitidos alópatas con expediente en la Junta General de Títulos Médicos

\begin{tabular}{|c|c|c|c|c|}
\hline CARPETA & NOMBRE & DEPARTAMENTO & $\begin{array}{l}\text { MUNICIPIO } \\
\text { PRINCIPAL }\end{array}$ & OTROS MUNICIPIOS \\
\hline 3229 & Alvarado, Cruz María & Valle del Cauca & Jamundí & Alcalá, Bogotá \\
\hline 3233 & Arango H., Antonio & Valle del Cauca & Florida & La Pradera, Bogotá \\
\hline 3231 & $\begin{array}{c}\text { Arenas V., Francisco } \\
\text { Julio }\end{array}$ & Valle del Cauca & Ulloa & Alcalá, Cali \\
\hline 3232 & $\begin{array}{c}\text { Arenas V., Francisco } \\
\text { Julio }\end{array}$ & Valle del Cauca & Ulloa & $\begin{array}{c}\text { Versalles, Trujillo y } \\
\text { Riofrío }\end{array}$ \\
\hline 3237 & Barrera, Lula & Cundinamarca & Quipile & Bogotá \\
\hline 3159 & Guinard, Fernando & Cundinamarca & La Vega & Nocaima, Vergara \\
\hline 3161 & Gutiérrez, Anaís & Magdalena & Aracataca & Valledupar \\
\hline 3164 & Herrán,Luis Eugenio & Cundinamarca & Girardot & Tocaima \\
\hline 3177 & Monteros E., Carlos A. & Valle del Cauca & Roldanillo & Cerrito \\
\hline 3181 & Perlaza T., Agustín & Valle del Cauca & La Florida & \\
\hline 3186 & Rincón, Benito & Cundinamarca & Sasaima & \\
\hline 3184 & Rodríguez A., Antonio & Cundinamarca & Tenjo & Bogotá, Suba \\
\hline 3293 & Rodríguez, Julio & Tolima & Guamo & Ibagué \\
\hline 3187 & Rojas, Marco Tulio & Santander & Guavatá & \\
\hline 3189 & Romero Plazas, Isaías & Cundinamarca & Villeta & \\
\hline 3188 & Romero Plazas, Isaías & Tolima & $\begin{array}{l}\text { El Carmen de } \\
\text { Apicalá }\end{array}$ & \\
\hline 3190 & Rondín U., Antonio & Cundinamarca & Bogotá & $\begin{array}{c}\text { San Martin (Meta), } \\
\text { Anolaima }\end{array}$ \\
\hline 3159 & Ruiz, Juan Francisco & Cundinamarca & Sopó & \\
\hline 3193 & Téllez S., Francisco & Cundinamarca & Nemocón & \\
\hline 3200 & $\begin{array}{l}\text { Torrente Wilson, } \\
\text { Roberto }\end{array}$ & Valle del Cauca & Toro & Bogotá \\
\hline
\end{tabular}




\begin{tabular}{c|c|c|c|c}
\hline 3229 & Torres, Eleázar & Valle del Cauca & Cali & \\
\hline 3198 & $\begin{array}{c}\text { Trujillo, Juan } \\
\text { Nepomuceno }\end{array}$ & Tolima & Venadillo & \\
\hline 3197 & Vargas G., Manuel & Valle del Cauca & Alcalá & \\
\hline 3203 & Vega, Sinforoso & Cundinamarca & La Palma & Yacopi \\
\hline 3205 & Velasco, Avelino & Valle del Cauca & Tuluá & Caicedonia \\
\hline 3207 & Velásquez B., Pedro & Valle del Cauca & Cali & \\
\hline 3208 & Velásquez, Luis E. & Cundinamarca & Ortega & Cunday, Viotá \\
\hline 3204 & Vergara Canales, & Cundinamarca & Bogotá & Madrid, La Mesa, \\
\hline 3209 & Eila, Jesús María & Valle del Cauca & Ansermanuevo Dios & \\
\hline 3212 & Villegas, Roberto & Tolima & El Libano & \\
\hline 3216 & Zapata Serna, Arcesio & Antioquia & Medellín & Betulia, Maceo \\
\hline 3218 & Zapata, Felipe & Valle del Cauca & Yotoco & Cali, Bogotá \\
\hline
\end{tabular}

Fuente: AGN, Colombia, fondo "Teguas".

La visita a algunos de estos expedientes nos servirá para mostrar la situación de los médicos permitidos en tanto trabajadores insertos en comunidades locales.

Una muestra de la divergencia de criterios al otorgar las licencias a los "médicos permitidos" es el caso de Eduardo Vergara Canales, autorizado por el Gobierno para ejercer la medicina, no la cirugía, en cualquier localidad del departamento de Cundinamarca, donde se comprobara legalmente que no había médico graduado en ejercicio. Durante la Guerra de los Mil Días ejerció distintas funciones como médico:

[... médico de las fuerzas acantonadas en Madrid [... ], médico de la ambulancia de la Provincia de Oriente, en el Hospital de La Mesa, que tuve el honor de trabajar durante un año diariamente con los doctores Próspero Cervantes, Leopoldo Cervantes y Marco A. Iriarte Rocha [...]; fui promovido al Hospital de Facatativá a donde trabajé hasta la terminación de la Guerra; por último, en Agua de Dios, bajo la dirección del eminente médico Montoya Flores, quien tuvo ha (sic) bien encargarme de la consulta y visitas a domicilio. ${ }^{14}$

En su calidad de médico sin diploma con buenas relaciones entre la élite gobernante, es evidente que el prestigio de Vergara como médico de oficio dependió en gran parte de esas relaciones. El médico que él menciona en su solicitud de revalidación de licencia para el ejercicio de la medicina en Bogotá, el Dr. Juan Bautista Montoya y Flórez, era uno de los hombres más influyentes en Colombia a comienzos del siglo XX. Pero la argumentación de Vergara no se compone solamente de buenas relaciones, que pesaban mucho a la hora de obtener una licencia, Vergara también añade su experiencia:

Hace más de treinta años ejerzo la profesión y ya por la lucha de la vida y amarguras que he pasado para conseguir honradamente el pan para mis niños y esposa, no me encuentro en condiciones de poderme ir a un destino, llevando cinco niños en momentos como estos, en que se atraviesa una mala situación. ${ }^{15}$

14 ARCHIVO GENERAL DE LA NACIÓN, fondo Teguas, carpeta 3204, folio 6. En adelante, citaremos las fuentes de este archivo de forma abreviada, así: AGN, Teguas, c. 3204, f. 6.

15 AGN, Teguas, c. 3204, f. 6. 
La relaciones sociales y políticas, las recomendaciones de notables, vecinos, clientes y profesores de medicina, el argumento de una larga experiencia y de la aceptación por parte de la comunidad... todos esos factores son comunes en las formas y en las retóricas de legitimación del ejercicio médico de los sin diploma. Lo llamativo, singular e ilustrativo en el caso de Vergara es precisamente que le fuera revalidada la licencia, el 27 de mayo de 1924, sin especificar un lugar de ejercicio. De su pequeño expediente se puede colegir que su práctica médica era legal en Bogotá, capital de la república y distrito donde ejercían numerosos médicos graduados.

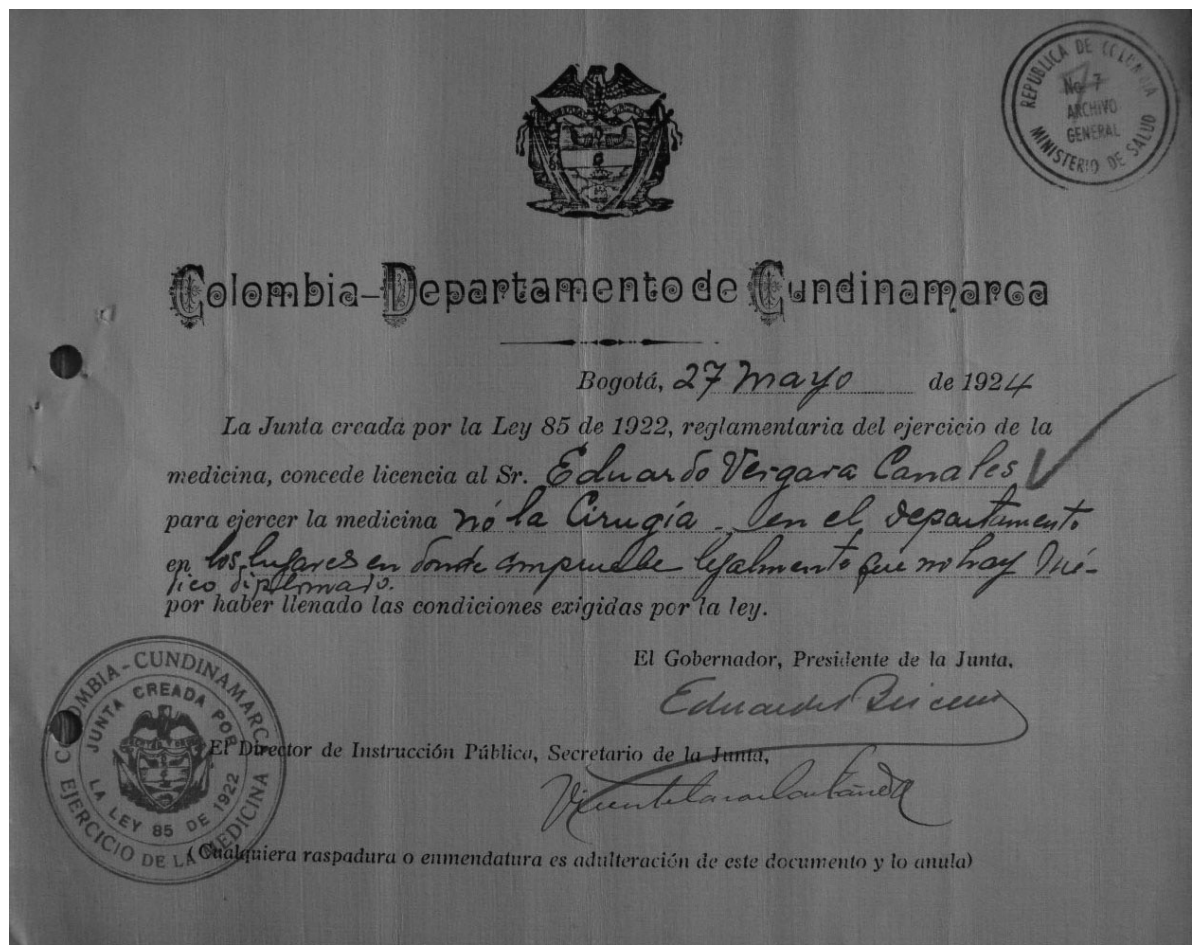

Figura 1 - Licencia del médico permitido Eduardo Vergara Canales. ${ }^{16}$

\section{El médico permitido Francisco Téllez S.}

El 9 de agosto de 1926, el señor Francisco Téllez S., colombiano, residente en Nemocón, Cundinamarca, presentó a la JCTM una nueva solicitud en la que recuerda las que él mismo hiciera el 14 y el 28 de junio de ese mismo año. ${ }^{17}$ Cuenta Téllez que el alcalde del municipio le impedía ejercer la medicina, con lo cual desconocía su condición de "médico permitido", poseedor de licencia expedida por la JCTM y revalidada el 24 de mayo de $1921 .{ }^{18}$ Con la expedición de la Ley 85 de 1922, las autoridades locales le exigieron a Téllez que refrendara su licencia. Él alegó que esa última ley no exigía, a quienes ya las tenían, refrendar las licencias. Argumentaba que tenía derecho a trabajar porque no se le podía aplicar la ley de manera retroactiva, según una tesis muy común en los alegatos de los permitidos, con ocasión de la negación de licencias:

[...] de acuerdo con la Constitución, los derechos adquiridos no pueden ser vulnerados por leyes posteriores y por tanto el derecho

16 AGN, Teguas, c. 3204, f. 7.

17 AGN, Teguas, c. 3193, f. 1.

18 AGN, Teguas, c. 3193, f. 3. Ver figura 2. 
de recetar que adquirí de acuerdo con la ley de 1920 [la 67] no puede desconocerse por la autoridad encargada de proteger a las personas y sus bienes $[\ldots] \cdot{ }^{19}$

Téllez redactó y envió dos oficios al gobernador de Cundinamarca, en 1926 (9 y 13 de agosto), para pedir que se le respetara su licencia de médico. ${ }^{20}$ En ambos intenta que el superior directo y natural del alcalde de Nemocón le ordene a este funcionario que no le impida el ejercicio de su ocupación. También utilizó el recurso legal consistente en hacer certificar su trabajo mediante un memorial firmado por vecinos de la comunidad. ${ }^{21}$ El de Téllez lo firmaron 38 personas, y en él se afirma que desde hacía unos 35 años trabajaba como boticario y “médico permitido" en la localidad de Nemocón, departamento de Cundinamarca. ${ }^{22}$ Para estos ciudadanos Téllez era un "doctor" competente que había curado a muchas personas, con "especial acierto" al tratar niños enfermos, habiendo curado enfermos de tifo, y que recetaba a los más pobres sin exigir "óbolo ninguno". ${ }^{23}$

Acompañó su solicitud con un memorial redactado y firmado por él, en Bogotá, el 3 de mayo de 1921, dirigido a la Junta Seccional de Títulos Médicos de Cundinamarca, en el cual declaró que ejercía la medicina desde hacía 25 años (¿desde 1896?), y que le había sido expedida "certificación de idoneidad" por parte de los médicos Manuel Plata Azuero y José Vicente Uribe, miembros de la Academia de Medicina de Colombia. Pero en este último documento se lee que su fecha de expedición es 15 de julio de 1875; además, los dos médicos certificaron que Téllez poseía conocimientos de medicina y farmacia y que había practicado en el Hospital San Juan de Dios de Bogotá, lo mismo que en el consultorio particular que ellos mismos habían abierto en Bogotá. El 2 de enero de 1907, en Zipaquirá, obtuvo licencia para el ejercicio de la medicina y la farmacia, ajustada a la Ley 12 de 1905 y al Decreto 592 del mismo año. ${ }^{24}$ El 24 de mayo de 1921 le revalidaron la licencia que lo autorizaba a ejercer la medicina y la farmacia en Nemocón. ${ }^{25}$

El 10 de julio de 1930, Francisco Téllez emprendió diligencias legales para hacer renovar su licencia. Durante esa semana hizo firmar por tres notables del pueblo sendas declaraciones según las cuales se hacía constar ante la alcaldía que ejercía como médico permitido en Nemocón hacía más de veinte años; que el único despacho permanente de drogas existente hasta ese momento en el municipio era de su propiedad; que aunque un médico graduado, el Dr. Carlos Julio Guerra, residía allí, no tenía "despacho de drogas" ni había anunciado su consultorio, pues se dedicaba a sus minas de carbón y a "otros negocios de campo"; finalmente, que los servicios de Téllez como médico eran satisfactorios. En otro certificado del 21 de julio de 1930, el alcalde de Nemocón aseveró que aunque otro médico graduado, el Dr. Rafael Cárdenas, tenía una farmacia en ese municipio y lo visitaba con frecuencia, no residía allí, sino en Zipaquirá, y su botica permanecía mucho tiempo cerrada sin atención al público. ${ }^{26} \mathrm{El} 8$ de julio

19 AGN, Teguas, c. 3193, f. 1.

20 AGN, Teguas, c. 3193, f. 1-2.

21 Ley 83 de 1914, artículo 6, parágrafo: “[... ] las autoridades permitirán el ejercicio de la medicina (no de la cirugía), cuando así lo solicitaren por lo menos veinticinco vecinos honorables y la autoricen dos médicos graduados residentes en la localidad".

22 AGN, Teguas, c. 3193, f. 4.

23 AGN, Teguas, c. 3193, f. 4

24 AGN, Teguas, c. 3193, f. 7.

25 AGN, Teguas, c. 3193, f. 9.

26 AGN, Teguas, c. 3193, f. 14. 
el cura párroco de Nemocón certificó lo mismo. ${ }^{27}$ El 31 de marzo de 1932 la Junta Central de Títulos Médicos revalidó la licencia de Francisco Téllez. ${ }^{28}$

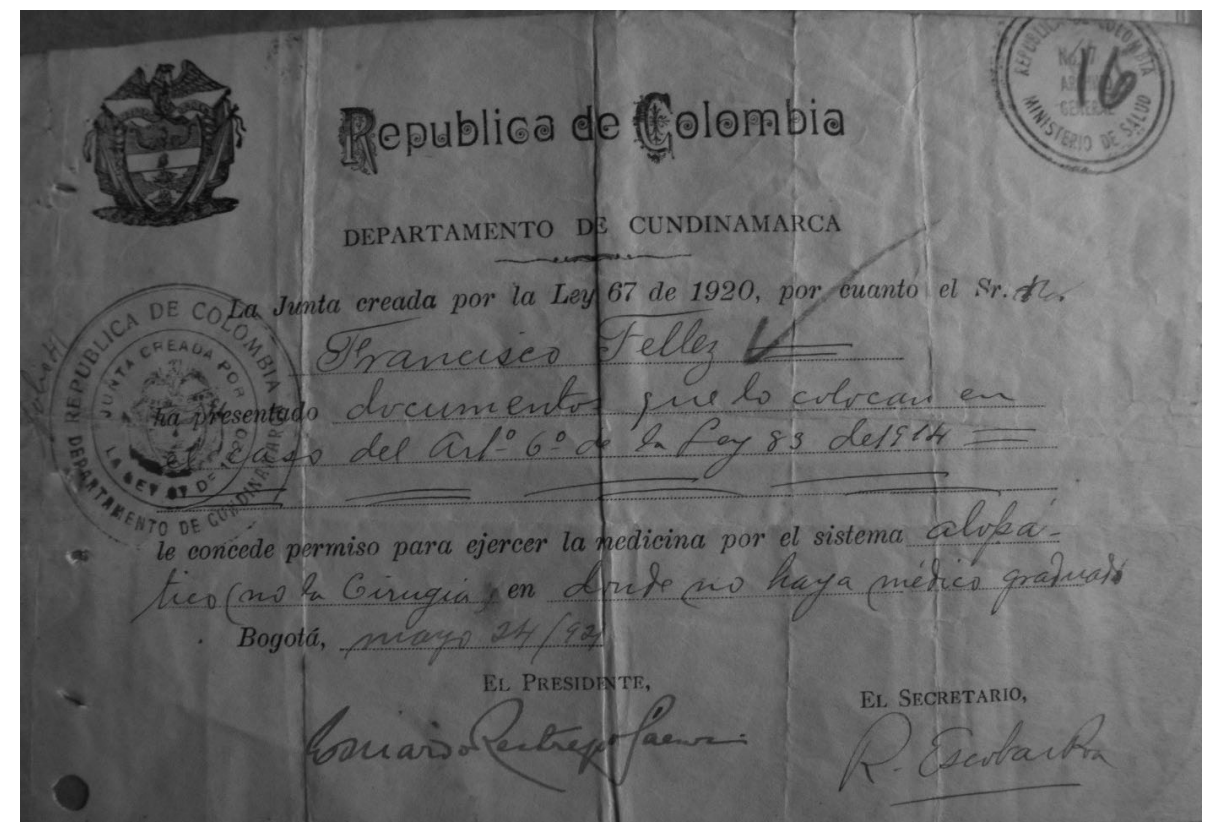

Figura 2 - Licencia de Francisco Téllez, revalidada el 24 de mayo de 1921.29

\section{Francisco Arenas: médico y farmaceuta permitido y funcionario oficial}

El Sr. Francisco Julio Arenas V., "farmacéutico titulado", mediante la resolución $n^{\circ} 41$ de la Junta Departamental de Títulos Médicos del departamento del Valle del Cauca (JDTMV), del 13 de noviembre de 1925, había obtenido en Cali licencia para el ejercicio de la medicina, no la cirugía, en el corregimiento de Sucre,,$^{30}$ municipio de Alcalá. Esta licencia fue revalidada el 15 de noviembre de $1928 .{ }^{31}$

El 23 de septiembre de 1925, 26 vecinos de la localidad de Sucre, entre ellos varios notables, firmaron una petición y la presentaron al gobernador del departamento para que le concediera licencia a Arenas para el ejercicio de la medicina y la farmacia. ${ }^{32}$ Para presentar la petición, los vecinos se basaban en el parágrafo del artículo $2^{\circ}$ de la Ley 85 de 1922, ya citado. Asimismo, citaron el artículo $3^{\circ}$ del Decreto reglamentario $n^{\circ} 355$ de 1923: "Para obtener licencia, [... ] se necesita acreditar la falta de médico diplomado y acompañar certificación del Alcalde respectivo, sobre honorabilidad del peticionario y de los vecinos que soliciten la licencia".

Por resolución de la JDTMV, el 23 de octubre de 1930 se revalidó la licencia de médico de Francisco Arenas, lo que le permitía ejercer en el municipio de Ulloa, Valle. Esta solicitud de revalidación, con el correspondiente pago de 100 pesos, la presentó ante el director general de educación pública, el 28 de julio de 1930, es

27 AGN, Teguas, c. 3193, f. 15.

28 AGN, Teguas, c. 3193, f. 9.

29 AGN, Teguas, c. 3193, f. 7.

30 Actualmente, y desde 1925, el corregimiento de Sucre es el municipio de Ulloa, Valle del Cauca. En el expediente de Francisco Julio Arenas V., ambos nombres se usaban todavía indistintamente. AGN, Teguas, c. 3231, f. 22.

31 AGN, Teguas, c. 3231, f. 8.

32 AGN, Teguas, c. 3231, f. 17. 
decir, cuando recién entraba en vigencia la Ley 35 de 1929 y su decreto reglamentario (1099 de julio de 1930). La Junta Central de Títulos Médicos confirmó la validez de esta nueva licencia el 3 de septiembre de 1930.33 Como parte de estos trámites, el alcalde de Ulloa, Guzmán Botero, expidió un memorial de recomendación en el que subrayaba los méritos de Arenas:

[... ] un ciudadano correcto, de intachable reputación y esquisito (sic) don de gentes, sino [un] profesional competente en la ciencia de la medicina y aún de la cirugía, pues si bien es cierto que esta última le está restringida por ministerio de la ley, también lo es que con la facultad que le concede la ley 83 de 1914, ha practicado varias autopsias en este municipio con buenos resultados para las investigaciones y sin tacha por los funcionarios superiores. Además, es un hábil farmaceuta diplomado, habiendo podido constatar que es muy solicitado en su profesión y ha prestado invaluables servicios $\left[\ldots . . .^{34}\right.$

Según Guzmán, en el municipio de Ulloa, Arenas había “[...] desempeñado en distintas ocasiones con actividad, celo y competencia, los puestos de Médico escolar nombrado por el Departamento e Inspector de Higiene y Salubridad Públicas designado por el Concejo municipal". 35

El 12 de noviembre de 1928, el señor Francisco Julio Arenas V. solicitó a la JDTMV que le permitieran ejercer la "pequeña cirugía". Dice Arenas en su solicitud:

[desde 1925] he practicado en asocio con el Dr. Carlos H. Medina algunas operaciones de cirugía, porque este me ha llamado a que le haga su compañía y luego me ha dejado encargado de estos enfermos bajo su dirección, lo que me parece he cumplido en debida forma como puede verse en el certificado que le adjunto.

[... como en esta no hay médico graduado y en caso de necesitarse alguna pequeña operación de cirugía hay que ocurrirse a poblaciones muy distantes donde los hay, y por ocurrirse que con frecuencia hay heridos a quien suturar heridas y practicarles algunas operaciones sencillas de las cuales me creo competente para ejecutar, [...] solicito licencia para practicar estas pequeñas operaciones en esta población por no haber médico autorizado para ello.

Me ha movido esta petición el que de la oficina de la Inspección de policía de este lugar he sido llamado varias veces, como médico licenciado, para reconocer y ver el modo de sanarlos por tener venas rotas y algunos otros asuntos en que se necesita alguna operacioncita sencilla; y no he podido ayudar en nada por no tener licencia para ello, porque solo por oficio $\mathrm{n}^{\circ} 1354$ se me concedió el permiso para poner algunas inyecciones por la Dirección de Higiene. ${ }^{36}$

La solitud para ejercer "pequeñas cirugías" parece haber perjudicado el ejercicio legal de Francisco Arenas. En efecto, el $1^{\circ}$ de febrero de 1929 "la junta inspectora de títulos médicos del departamento del Valle" le negó la solicitud de revalidación de licencia (presentada en noviembre de 1928) y lo dejó sin licencia durante meses. Arenas apeló ante la Junta Central de Títulos Médicos del Ministerio de Educación Nacional y le respondieron negativamente el 8 de octubre de 1930.37

33 AGN, Teguas, c. 3231, f. 21.

34 AGN, Teguas, c. 3231, f. 7.

35 AGN, Teguas, c. 3231, f. 7.

36 AGN, Teguas, c. 3231, f. 10.

37 AGN, Teguas, c. 3231, f. 18. 
Esto muestra lo engorroso de los trámites que debían seguir los médicos sin diploma para obtener la licencia para el ejercicio de la medicina. Los podían dejar incesantes durante meses, y mientras tanto la comunidad local permanecía sin médico. En el caso de Arenas, como atendía la única farmacia de la localidad, es posible que por presión de su clientela y por el apoyo de la comunidad continuara parte de su ejercicio en la ilegalidad.

A finales de agosto de 1928 el inspector y el cura párroco de Ulloa dieron testimonio de las habilidades clínicas de Arenas, al presentarlo como perito médico de dos casos de locura, uno de los cuales, dicen, fue curado por él. ${ }^{38} \mathrm{El}$ 8 de noviembre de 1928, el inspector de policía del corregimiento de Sucre y su secretario habían firmado y enviado una petición a la JDTMV del Valle para que autorizara las pequeñas cirugías a Arenas. ${ }^{39}$ Con la misma intención, el médico graduado Carlos H. Medina P. certificó, ante la misma Junta, el 10 de noviembre de ese año, que Arenas poseía botica en Sucre (o Ulloa) y que era idóneo para el ejercicio de la farmacia y la medicina, por lo tanto debería obtener su licencia. No mencionó el Dr. Medina las pequeñas cirugías. El 21 de agosto de 1928, un enfermo procedente de Pereira dio testimonio ante la JSTM de haber sido diagnosticado y curado de cólera asiático y paludismo, en Ulloa, por Francisco Arenas. ${ }^{40}$ En septiembre de 1931 le fue revalidada la licencia que le habían otorgado en octubre de 1930. El 13 de marzo de 1936 hubo una revalidación por parte de la Junta Central de Títulos Médicos; ${ }^{41}$ hubo otra el 28 de mayo de $1937 .{ }^{42}$

El 2 de diciembre de 1933, Francisco J. Arenas había solicitado al director departamental de higiene del Valle que le permitiera ejercer la medicina por fuera del municipio de Ulloa, donde estaba autorizado, para ir trabajar al municipio de Andalucía o al de Riofrío, cercanos a la ciudad de Tuluá. ${ }^{43}$ En su memorial explicó la necesidad de su traslado. Por ser pobre, padre de familia y por estar tan alejada la población donde vivía y trabajaba (Ulloa, Valle) con respecto a ciudades más importantes, Arenas se veía en la incapacidad de continuar la educación de sus hijos. En Ulloa solo había estudios hasta cuarto de primaria. Ambos niños, Guillermo y Manuel, ya habían repetido el $4^{\circ}$ grado, y necesitaban vivir en una ciudad donde pudieran continuar estudiando. Arenas sugirió que esa ciudad podía ser Tuluá, donde los niños ya tenían cupos en el "Gimnasio del Pacífico". Por otra parte, Tuluá estaba muy cerca de dos pueblos donde no había médico graduado y donde el médico permitido podría ejercer la medicina y abrir su farmacia. Además, como ya tenía las respectivas licencias vigentes (de médico y de farmaceuta), solo requería autorización del traslado.

Era muy lento y dispendioso el trajín administrativo que debían seguir los médicos permitidos. Las autoridades le respondieron el 17 de abril de 1934, pero para decirle que escogiera uno de los dos municipios mencionados y que acompañara un nuevo memorial con una carta del alcalde del municipio escogido, en la que se certificara que no había allí médico graduado en ejercicio. ${ }^{44}$ Lo que significaba iniciar de nuevo todos los trámites.

En 1935, el mismo Francisco Arenas decidió su traslado a otro municipio, Versalles, en el mismo departamento, para lo cual solicitó un certificado del alcalde

38 AGN, Teguas, c. 3231, f. 13 y 14.

39 AGN, Teguas, c. 3231, f. 11.

40 AGN, Teguas, c. 3231, f. 15.

41 AGN, Teguas, c. 3231, f. 4.

42 AGN, Teguas, c. 3232, f. 1.

43 AGN, Teguas, c. 3232, f. 8 y 9.

44 AGN, Teguas, c. 3232, f. 10. 
de esa localidad que indicarla ausencia de médico graduado. ${ }^{45} \mathrm{El}$ oficio dirigido por Francisco Arenas al alcalde de Versalles data del 2 de agosto de 1935, fecha en la cual Arenas se desempeñaba como personero municipal de Ulloa. ${ }^{46}$

El 2 de agosto de 1935, Rubén Ospina, alcalde de Ulloa, certificó ante la JSTM que Arenas "ha desempeñado el cargo de médico escolar" en varias ocasiones, siempre nombrado y posesionado oficialmente; que en ese momento funge como personero municipal y que ha ejercido ese cargo varias veces; también cuenta que ha sido inspector escolar; hace constar que "el señor Arenas es un buen servidor público"; certificó su buen criterio, probidad, honradez y caridad: "Me consta haberlo visto hacer toda clase de esfuerzos para salvar la vida de muchas personas misérimas (sic), únicamente guiado por el espíritu de caridad. En esta población el señor Arenas es sumamente apreciado por todos los ciudadanos". 47

El 23 de agosto de 1935, el alcalde de Versalles certificó la ausencia de médico graduado en ese municipio..$^{48} \mathrm{El} 24$ de noviembre del mismo año, Francisco Arenas le escribió a su amigo Tulio Enrique Tascón, quien se había posesionado el 12 de ese mismo mes como gobernador del Valle del Cauca, cargo que ejerció hasta el 3 de agosto de 1938. La solicitud de Arenas, de agosto de 1935, ante la JSTM del Valle para que se le autorizara trabajar como médico licenciado en Versalles, no había obtenido respuesta. Arenas le pidió entonces a su amigo el gobernador que intercediera. Pero también lo solicitó para otro asunto. La Comisión de Especialidades Farmacéuticas acababa de cancelar las licencias de dos medicamentos que producía artesanamente en su casa de Ulloa, donde tenía su botica y la "oficina" de esta. Arenas se presentó como "único fabricante en Colombia de Ungüento Neurastil y Nervi-curatintura", "preparados que tienen marca de fábrica registrada ante el Ministerio de industrias". Parece que el motivo de la cancelación de las licencias era la carencia de un laboratorio certificado por la Dirección Departamental de Higiene. Arenas sabía que le era imposible cumplir este requisito, pero pedía en su carta "un poco de tolerancia, pues la mayoría de los industriales somos pobres y, en tal caso, los únicos llamados a tener empresas industriales serían los capitalistas"; además, para él "no todas las especialidades requieren [laboratorio industrial] para su preparación". Las suyas "solo requieren una sala para preparar y embalaje". Según Arenas, el ungüento Neurastil y la tintura Nervi-cura eran fáciles de preparar y empacar y el personal que lo hacía era él mismo, su esposa y uno de sus hijos, "personal sano de enfermedades contagiosas". Arenas presentó los detalles de las preparaciones oficinales e informaba que con sus propios recursos ha habilitado una sala especial en su casa para desarrollar su "pequeña industria". Solicitó que el director departamental de higiene (Dr. Emilio Quintero, copartidario y amigo) visitara esas instalaciones y constatara por sí mismo la calidad.

[...] que no se me perjudique en mi pequeña industria; pues no me ruboriza manifestar a Ud. que mi mala situación en gran parte es ocasionada por la directa intervención en la política, que como Ud. sabe, "ser liberal es un honor que cuesta", así lo dijo nuestro llorado conductor Uribe Uribe. ${ }^{49}$

45 AGN, Teguas, c. 3232, f. 11.

46 AGN, Teguas, c. 3232, f. 12.

47 AGN, Teguas, c. 3232, f. 12.

48 AGN, Teguas, c. 3232, f. 13.

49 AGN, Teguas, c. 3232, f. 15. 
El 28 de enero de 1936, Arenas todavía no se había mudado a otro municipio, vivía aún en Ulloa, a la espera de la revalidación de las licencias de médico y farmaceuta..$^{50}$ Pero en el interregno, más precisamente en diciembre de 1935, hubo una nueva reforma legal del sistema de títulos médicos, expresada en la Ley 67 de ese año. El artículo $8^{\circ}$ de esta ley, demasiado ambiguo, lo deja en gran incertidumbre respecto al trámite de sus licencias:

La Junta Central de Títulos Médicos podrá organizar provisionalmente cuatro Juntas Seccionales, fijándoles la correspondiente jurisdicción e integrándolas así: por el Director Departamental de Higiene y por dos médicos designados por la Junta Central, que gozarán de una remuneración que fijará el Ministerio de Educación Nacional y que incluirá en su presupuesto.

En ese momento, la licencia más reciente de Arenas databa del 9 de septiembre de $1931 .^{51}$ En ella aparece pegada una foto suya, no muy nítida, en la que se ve a un hombre blanco, de entre 30 y 40 años de edad.

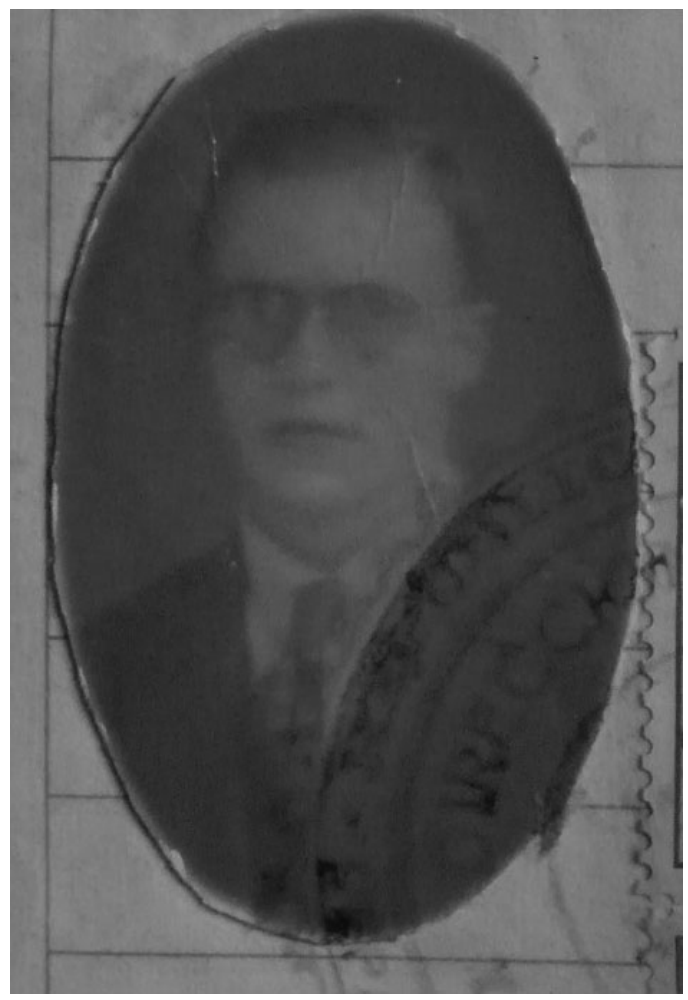

Figura 3 - Retrato fotográfico de Francisco Arenas.52

El 7 de diciembre de 1936, Arenas le pidió al alcalde, Manuel J. Barona M., al presidente del Concejo municipal, Delfín Rodríguez Toro, y a dos ciudadanos honorables, Alfonso Navarro y Germán Arboleda, todos de Ulloa, que declararan a su favor, pues así se lo exigía la JCTM para tramitar la renovación de su licencia. Los cuatro declararon ese mismo día y en los mismos términos. Dieron testimonio de conocer de mucho tiempo atrás a Francisco Arenas, como médico, farmaceuta y funcionario municipal en varios cargos, entre ellos el de médico oficial. También dieron fe de su buena conducta, moralidad y caridad. Lo novedoso de estas 
declaraciones es que todas subrayan los beneficios de Arenas a su comunidad por sus servicios de obstetricia. También le certificaban oficialmente los cargos que durante los últimos 11 años había desempeñado en el municipio de Ulloa.53

En febrero de 1937 todavía no le habían renovado la licencia. ${ }^{54}$ Esta le fue revalidada por la resolución 76 del28 de marzo de 1937,55 y parece que habían autorizado a Arenas para trabajar en otros municipios del Valle del Cauca donde no hubiere "médico titulado establecido". También aparece una nueva solicitud de revalidación de licencia que data del 22 de agosto de $1939 .{ }^{56}$

Así transcurrieron unos ocho años sin documentación sobre Francisco Arenas en el fondo "Teguas". Pero él mismo cuenta, en 1947, que durante ese tiempo estuvo trabajando, primero en Riofrío y luego en Trujillo. En ese año varios acontecimientos lo obligaron a demandar la renovación de sus credenciales. ${ }^{57}$

El Dr. Alonso Madriñán Caicedo, médico graduado que dirigía la Comisión Sanitaria Rural formada, en 1947, para atender de manera ambulatoria los municipios de Bolívar, Trujillo y Rio frío, certificó el 6 de diciembre de ese año que, aunque él había sido nombrado jefe de tal comisión para atender las zonas rurales de los tres municipios, y que al haber unos 25.000 habitantes solamente en Trujillo, "diseminados en extenso territorio y clima malsano", Arenas prestaba invaluables servicios a la comunidad de ese lugar. La presencia de Madriñán como médico graduado impidió que se le renovara la licencia a Arenas. Más tarde, el mismo Madriñán envió telegramas a la Junta Central de Títulos Médicos y a la Junta Seccional del Valle del Cauca para insistir en el excelente trabajo de Arenas, y en que este no estorbaba el suyo sino que lo complementaba y aligeraba..$^{58}$ Por su parte, el alcalde y el personero municipales de Trujillo certificaron el 8 de junio de 1948 que en ese lugar no existía "médico graduado establecido", y que esos servicios los había prestado Arenas durante los últimos diez años. 59

El 2 de julio de 1948 la Junta General de Títulos Médicos le negó a Arenas la revalidación de su licencia, prohibiéndole trabajar como médico en Trujillo. ${ }^{60}$ En agosto del mismo año, Arenas envió más testimonios de personas que declaraban conocerlo como médico de Trujillo y otros municipios del Valle del Cauca. Recibió nuevas respuestas negativas. En ese momento, Arenas llevaba unos 23 años ejerciendo la medicina con licencias otorgadas por el Gobierno. ${ }^{61}$ Las negativas reiteradas parecían obedecer, en términos legales, a la presencia del médico graduado Alonso Madriñán Caicedo, médico de la Comisión Sanitaria Rural. Este insiste ante la Junta Central de Títulos Médicos, en telegrama del 28 de marzo de 1949, en que la labor del señor Arenas no lo perjudicaba en nada y que, en consecuencia, le deberían renovar la licencia. La respuesta de esa entidad siempre fue negativa. Entonces Arenas decidió, el 4 de abril de 1949, contratar los servicios de un abogado, Jesús María Correa Rengifo, que lo representara para apelar las resoluciones negativas de la JCTM. ${ }^{62}$ Correa argumentó en varias ocasiones a favor de la legitimidad del trabajo de Arenas:

\footnotetext{
53 AGN, Teguas, c.3232, f. 20, 21, 22, 23, 24 y 26.

54 AGN, Teguas, c.3232, f. 27.

55 AGN, Teguas, c.3232, f. 38.

56 AGN, Teguas, c. 3231, f. 5 .

57 AGN, Teguas, c.3232, f. 29.

58 AGN, Teguas, c.3232, f. 31.

59 AGN, Teguas, c.3232, f. 34 .

60 AGN, Teguas, c.3232, f. 38.

61 AGN, Teguas, c.3232, f. 39-41.

62 AGN, Teguas, c.3232, f. 49.
} 
[... ] un médico oficial que está desempeñando determinadas funciones oficiales y sometido en un todo a ellas, y que por lo tanto, en sana justicia y ante la letra fría [...] de la ley no puede considerarse en la extensión del vocablo como un médico establecido en ese municipio, siendo así que el doctor Arenas no se encuentra ocasionalmente en dicho municipio, sino que se encuentra radicado en él, en donde por espacio de 24 horas diarias está a disposición del público que tiene fe en él, que tiene confianza en él. [...]

Explicaba el abogado en su memorial de cuatro páginas (presentado oficialmente el 21 de abril) que esa confianza pública se basaba en lo económico, lo moral y lo científico. La clientela de Arenas era gente pobre que confiaba en él como médico y como persona, por sus 22 años de ejercicio entre los campesinos, labor que había emprendido por su propia voluntad y no porque lo enviaran en misión oficial; en lo económico, esta confianza significaba que muchas veces el pago de honorarios se tenía que diferir, lo que sería imposible con un médico recién llegado, menos si era un médico del gobierno que en cualquier momento podría verse obligado a partir. ${ }^{63}$

Nada de esto sirvió. Las repuestas siguieron siendo negativas: la de la apelación del 8 de junio de 1949; ${ }^{64}$ la de la apelación del abogado Correa del 15 de junio de $1949,{ }^{65}$ nuevamente negada por la JCTM el 10 de agosto del mismo año. ${ }^{66}$ Finalmente, el 21 de febrero de 1950 el propio ministro de Higiene, Jorge E. Cavelier, emitió una resolución para refrendar todas las anteriores que la JCTM había expedido en contra del ejercicio médico de Francisco Arenas.

\section{Conclusión}

El caso del médico permitido Francisco Arenas es uno de los más ilustrativos, porque su práctica atraviesa varias coyunturas históricas con sus correspondientes legislaciones y agudizaciones del debate de los graduados en contra de los sin diploma. Sin embargo, los casos evocados en este artículo presentan elementos en común acerca de las formas de legitimación de la práctica de los médicos permitidos. Entre estas hay que enumerar: el desempeño de cargos públicos, incluso los de médico oficial del municipio, director del hospital o médico de los ejércitos oficiales en campañas militares; ${ }^{67}$ la aceptación por parte de la comunidad ("vecinos", clientela privada, notables del pueblo y médicos graduados); las filiaciones políticas y los vínculos de amistad con personas influyentes; la experiencia práctica como argumento de idoneidad, que se expresaba comprobando el desempeño del oficio durante años, por medio de las certificaciones antiguas y nuevas de médicos reconocidos socialmente como profesores de las facultades de medicina y como miembros de las academias científicas, quienes certificaban ante las autoridades y la sociedad en general las competencias médicas de los permitidos; las prácticas médicas al lado de algún médico graduado, entre ellas la

63 AGN, Teguas, c. 3232, f. 50 y 51.

64 AGN, Teguas, c. 3232 , f. 52.

65 AGN, Teguas, c. 3232, f. 53.

66 AGN, Teguas, c. 3232, f. 54.

67 El trabajo de los médicos permitidos y los conflictos que generaba en los pueblos ha sido ilustrado en una tesis de historia acerca de los modelos sanitarios en una importante región minera de Colombia: GALLO, Óscar. "Modelos sanitarios, prácticas médicas y movimiento sindical en la minería antioqueña: el caso de la empresa minera El Zancudo 1865-1948". (Tesis de Maestría en Historia, Universidad Nacional de Colombia, 2010). 
cirugía y la obstetricia; ${ }^{68}$ las certificaciones de decencia, virtudes morales y caridad expedidas por autoridades municipales y curas párrocos; la elaboración y venta de remedios de patente o "específicos", en ocasiones autorizados por la Comisión de Especialidades Farmacéuticas y patentados por el Ministerio de Industria, ${ }^{69}$ y el trabajo como peritos en casos penales. ${ }^{70}$

Es muy reductora la concepción según la cual la medicalización de una sociedad puede medirse por el grado de la presencia de la medicina universitaria en las pequeñas ciudades o en las regiones apartadas de las ciudades capitales. En contra de esto, las evidencias presentadas muestran que las prácticas de los permitidos se realizaban en pueblos humildes en donde no había médico graduado, y esto se debía en parte a que los médicos graduados no querían trabajar en lugares en donde la clientela era pobre y escaseaban las oportunidades de desarrollo de una profesión liberal. Coincide, en todo caso, que los departamentos colombianos que más producían riqueza eran los que contaban con más médicos graduados y con más médicos de todo tipo. La Tabla 2 ilustra esta situación. De ella debemos resaltar la posición del departamento de Antioquia, en 1934, con unos cien municipios, con más de un millón de habitantes y con unos trescientos médicos, lo que arrojaría un promedio muy aproximado de un médico por cada 3.700 habitantes para el departamento más opulento del país. Al constatar que la presencia médica se concentraba en las cabeceras urbanas y que los pocos graduados preferían las grandes ciudades, se puede inferir que en la mayor parte del territorio entre 1900 y 1940 la población no tenía acceso a cuidados médicos y que la presencia de la medicina universitaria era muy débil. Esto último da un tinte mucho más dramático a las angustias que vivían los médicos permitidos en los procesos de validación y revalidación de sus licencias, para poder trabajar y defender su inserción social en las comunidades a las que pertenecían como ciudadanos y como cuidadores.

Tabla 2

Resumen del registro de médicos por departamentos, intendencias y comisarías, Colombia, 1934.

\begin{tabular}{|c|c|c|c|c|c|c|c|}
\hline $\begin{array}{l}\text { DEPARTAMENTO/ } \\
\text { INTENDENCIA/ } \\
\text { COMISARÍA }\end{array}$ & 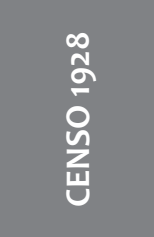 & $\begin{array}{l}y \\
\frac{8}{\alpha} \\
\frac{1}{a} \\
\frac{a}{a}\end{array}$ & $\begin{array}{l}y \\
8 \\
\frac{1}{u} \\
z \\
\text { ư }\end{array}$ & 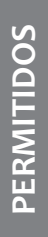 & $\frac{\frac{n}{5}}{\frac{n}{\frac{n}{4}}}$ & 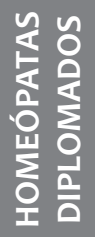 & 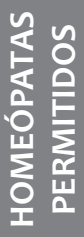 \\
\hline Antioquia & 1.011 .324 & 209 & 62 & 11 & 42 & 3 & 10 \\
\hline Atlántico & 242.810 & 90 & 6 & 1 & 8 & 1 & 13 \\
\hline Bolívar & 642.777 & 66 & 17 & 11 & 7 & & 2 \\
\hline Boyacá & 950.264 & 68 & 6 & 4 & 3 & & 3 \\
\hline Caldas & 624.201 & 113 & 10 & 4 & 6 & 7 & 3 \\
\hline Cauca & 317.782 & 16 & 2 & 3 & 6 & 1 & \\
\hline Cundinamarca & 1.056 .570 & 87 & 19 & 6 & 3 & 7 & 8 \\
\hline
\end{tabular}

68 El periodo histórico de la muestra analizada coincide con el que estudia Libia Restrepo al hacer la historia de la medicalización del nacimiento para una región de Colombia: RESTREPO, Libia. Médicos y comadronas o el arte de los partos. La ginecología y la obstetricia en Antioquia, 1870-1930. Medellín: La Carreta, 2006.

69 El problema de las medicinas de patente fue estudiado en: GARCíA, Víctor. Remedios secretos y drogas heroicas. Historia de los medicamentos en Antioquia 1900-1940. Medellín: Universidad Nacional de Colombia, 2008.

70 La historia del peritaje médico en Colombia ya cuenta con un aporte generoso. La autora muestra la participación de los “permitidos en estas prácticas médico-legales": DEL VALLE, Piedad. La medicalización de la justicia en Antioquia 1887-1914. Medellín: Universidad de Antioquia, 2010. 


\begin{tabular}{c|c|c|c|c|c|c|c}
\hline Huila & 207.034 & 18 & 2 & 3 & 2 & 1 & 1 \\
\hline Magdalena & 302.031 & 57 & 9 & 7 & 4 & & \\
\hline Nariño & 411.763 & 29 & 1 & 3 & 5 & & \\
\hline Norte del Santander & 328.872 & 43 & 1 & & 19 & 1 & \\
\hline Santander & 594.799 & 63 & 8 & 4 & & 2 & 1 \\
\hline Tolima & 444.593 & 41 & 12 & 1 & 6 & 6 & 7 \\
\hline Valle del cauca & 506.290 & 95 & 21 & & 10 & 7 & 4 \\
\hline Chocó & 85.399 & 10 & 1 & 1 & & & \\
\hline Meta & 19.320 & 9 & 3 & & & & 1 \\
\hline San Andrés y Providencia & 5.987 & 1 & 2 & 1 & & & \\
\hline Amazonas & 2.013 & & & & & & \\
\hline Arauca & 12.683 & 2 & & & & 1 & \\
\hline Caquetá & 14.154 & 3 & & & & & \\
\hline Putumayo & 16.520 & 1 & & & & & \\
\hline Vaupés & 9.332 & & & & & & \\
\hline Vichada & 11.117 & & & & & & \\
\hline La Guajira & 33.965 & & & & & & \\
\hline TOTALES & 7.851 .000 & 1.021 & 182 & 60 & 121 & 37 & 53 \\
\hline
\end{tabular}

Fuente: Anuario general de estadística, $1934 .^{71}$

Recebido em 16/02/2015 Aprovado em 23/08/2015 